\title{
Latanoprost with high precision, piezo-print microdose delivery for IOP lowering: clinical results of the PG2I study of $0.4 \mu \mathrm{g}$ daily microdose
}

This article was published in the following Dove Press journal:

Clinical Ophthalmology

\author{
Louis R Pasquale' \\ Shan $\operatorname{Lin}^{2}$ \\ Robert N Weinreb ${ }^{3}$ \\ James C Tsai ${ }^{4}$ \\ Robert L Kramm ${ }^{5}$ \\ Tsontcho lanchulev 5,6 \\ 'Department of Ophthalmology, \\ Harvard Medical School, \\ Cambridge, MA, USA; ${ }^{2}$ Department \\ of Ophthalmology, University \\ of California San Francisco, San \\ Francisco, CA, USA; ${ }^{3}$ Department \\ of Ophthalmology, University of \\ California San Diego, San Diego, CA, \\ USA; ${ }^{4}$ Department of Ophthalmology, \\ Mount Sinai School of Medicine, \\ New York, NY, USA; ${ }^{5}$ Eyenovia \\ Incorporated, New York, NY, USA; \\ ${ }^{6}$ Department of Ophthalmology, \\ New York Eye and Ear Infirmary, \\ Mount Sinai Medical School, \\ New York, NY, USA
}

Background: Topical high-precision piezo-print delivery of microdoses of latanoprost achieved significant IOP reduction consistent with the eyedropper effect but with a $75 \%$ reduced exposure to drugs and preservatives. Prostaglandin analogs are a mainstay glaucoma therapy. However, conventional eyedroppers deliver $30-50 \mu \mathrm{L}$ drops that greatly exceed the physiologic $7-\mu \mathrm{L}$ ocular tear film capacity. Eyedropper overdosing floods the eye with excess drug compounds and preservatives, resulting in ocular surface toxicity, periorbitopathy, and other well-characterized ocular side effects. Piezoelectric high-precision microdosing provides targeted delivery that can reduce exposure to both drug and preservatives compared to conventional eyedropper delivery, with the potential to deliver similar biologic effect.

Methods: Both eyes $(\mathrm{N}=60)$ of 30 healthy volunteers received single 8 - $\mu \mathrm{L}$ microdoses of $0.005 \%$ latanoprost ( $0.4 \mu \mathrm{g} ; \mu \mathrm{Rx}$-latanoprost) on the morning of Days 1 and 2 using a highprecision, piezo-print horizontal delivery system. Diurnal IOP was measured before and 2 days after microdosing. Main efficacy outcomes were diurnal IOP change after $\mu$ Rx-latanoprost microdosing and accurate microdosing success rates, and the primary safety outcome was adverse event (AE) incidence.

Results: $\mu$ Rx-latanoprost reduced baseline IOP by $26 \%$ and $30 \%$ at 1 and 2 days postadministration, respectively. Successful topical dosing was achieved in $100 \%$ of technician-assisted deliveries. All patients successfully self-administered microdoses after receiving training. Microdose administration was well tolerated and did not result in any AEs.

Conclusion: Microdosing of $0.4 \mu \mathrm{g}$ of $\mu \mathrm{Rx}$-latanoprost achieved significant IOP reduction. Lower ocular exposure with topical prostaglandin analog microdosing can enable new therapeutic opportunities for optimizing glaucoma treatment. Microdosing may also be beneficial in reducing ocular side effects associated with excessive drug product and preservatives often used to treat chronic ocular diseases such as glaucoma.

Keywords: microdosing, piezo-ejection system, latanoprost, IOP, IOP lowering, glaucoma, ocular drug delivery, Optejet, self-administration, usability

\section{Introduction}

Conventional eyedroppers deliver large and highly variable macrodoses containing $30-50 \mu \mathrm{L}$ of ocular medications. These volumes greatly exceed the reservoir and absorptive capacities of the eye, which range between 6 and $8 \mu \mathrm{L} .{ }^{1-3}$ Excess medication volumes are associated with ocular and systemic toxicity, ${ }^{4,5}$ which in the case of prostaglandin analogs include hyperemia, contact dermatitis, pigmentary changes, and periorbitopathy. ${ }^{6}$ With medications having cardiovascular activity, such as $\beta$-blockers 
(eg, timolol), overflow leakage through the nasolacrimal duct with systemic absorption can potentially cause bradycardia, respiratory depression, fatigue, and impotence. ${ }^{4,5}$ Drugs entering the body via the nasolacrimal apparatus will bypass hepatic first-pass metabolism similar to the intravenous administration, thereby increasing immediate systemic bioavailability. ${ }^{4}$

Reducing the excess volume of topically administered ocular medications by improving the precision of microvolumetric drug delivery can avoid problems associated with drug overflow and systemic absorption that occur after conventional eyedropper overdosing. Microdosing may also increase local drug bioavailability and absorption in the eye. We previously reported on the development of a high precision piezo-ejection microdroplet delivery system for administering small volumes of topical eye medications. ${ }^{7,8}$ This handheld electronic system delivered single-digit microliter volumes of topical medication. Results from two Phase II clinical trials demonstrated high efficiency of topical microdose delivery of ophthalmic mydriatic agents (ie, phenylephrine and tropicamide). In these studies, microdosing achieved equivalent pharmacodynamic effect as conventional eyedropper dosing, but with a $75 \%$ reduction in total drug dose and preservative delivery to the eye. High-precision microvolumetric drug delivery also ensures on-target delivery without spillage to the periocular regions. This is particularly important because only a minority of patients are able to accurately self-administer eye drops, even after having used them daily for $>6$ months. ${ }^{9-12}$

Standard eyedroppers of $0.005 \%$ latanoprost $(50 \mu \mathrm{g} / \mathrm{mL})$ typically dispense single-drop volumes of 32-34 $\mu \mathrm{L}$; a $32-\mu \mathrm{L}$ drop contains $1.6 \mu \mathrm{g}$ of latanoprost. Microdose administration can deliver a more physiologically appropriate $8-\mu \mathrm{L}$ microdose of $0.005 \%$ latanoprost that contains $0.4 \mu \mathrm{g}$ of active drug ( $\mu \mathrm{Rx}$-latanoprost). In this clinical trial, we evaluated microdosing of antiglaucoma medication using a horizontal delivery and piezo-print microdroplet administration system. We report that $\mu \mathrm{Rx}$-latanoprost microdosing significantly lowers IOP while administering only a fraction of conventional eyedropper doses.

\section{Methods}

\section{Subjects, screening, and enrollment}

We recruited healthy subjects aged 18 years or older without ocular pathology or underlying medical conditions. Female subjects of child-bearing age provided a negative serum pregnancy test prior to receipt of study medication. The study protocol was reviewed and approved by the Panama
Ministry of Health and the Ethics Committee of Punta Pacifica Hospital, which oversaw performance of the study at Clinica de Ojos Orillac-Calvo in Panama City, Panama, during March 2018. All subjects provided written informed consent prior to study participation. Study performance complied with the tenets of the Declaration of Helsinki.

At the screening visit, disease and medication histories were collected, and both eyes were examined grossly and by slit lamp. Patients who met study eligibility criteria underwent baseline unmedicated diurnal IOP measurements the day before the initiation of study medication delivery. Baseline IOP was measured at approximately 8 AM, 2 PM, 8 PM, and 7 AM the following day using Goldmann applanation tonometry.

\section{Study medication administration}

On Days 1 and 2, subjects were administered $0.4 \mu \mathrm{g}$ (8- $\mu \mathrm{L}$ microdose volume) of $0.005 \%$ latanoprost bilaterally each morning between 7 AM and 9 AM by a trained technician. After administration of medication, subjects completed ocular discomfort questions and underwent a slit lamp examination and diurnal IOP measurements $(1,7,12$, and 24 hours after morning microdosing) through 48 hours after receiving the first dose. This study was designed to investigate short-term diurnal IOP lowering.

During drug administration, the subject sat upright, and the technician held the piezo-ejection device approximately $3-5 \mathrm{~cm}$ in front of the eye. The subject was asked to fixate on the device's LED targeting light; then, the dosing button was pressed to emit a horizontal microdroplet stream to the eye (Figure 1). ${ }^{7,8}$ After completing the portion of the study in which medication effects were observed, subjects were individually provided training on microdose self-administration with the device to evaluate the rate of successful delivery and only comfort (not IOP-lowering effect). The subjects performed three consecutive self-administrations on three consecutive days.

\section{Outcome parameters}

The primary efficacy outcomes were as follows: 1) mean change in short-term diurnal IOP after microdosing with $8 \mu \mathrm{L}$ of $\mu \mathrm{Rx}$-latanoprost; and 2) successful microdose delivery rate, which were assessed by the technician administering the medication. Successful dosing was defined as accurate delivery of the medication to the ocular surface with no exposure to periocular tissues or the eyelids during blinking or head movement, without any direct physical contact of the device to the ocular surface. The primary safety outcome was the rate of ocular adverse events (AEs). 

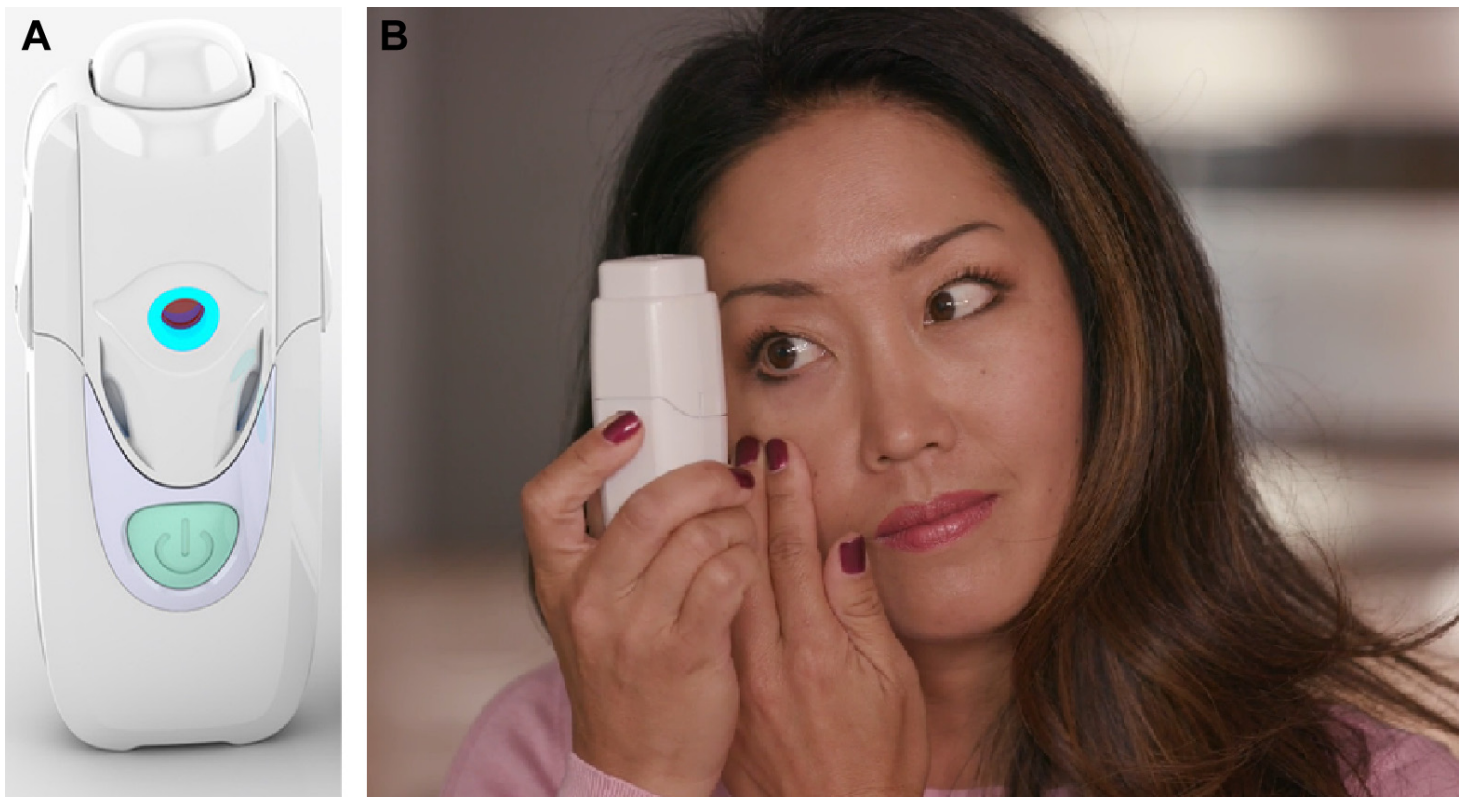

Figure I The two-part piezo-electric MiDD.

Notes: (A) The small handheld delivery system consists of an exchangeable upper section containing an ampoule reservoir prefilled with sterile ocular medication, which snaps into the lower ejection system containing system electronics and battery. (B) On push button activation, the MiDD releases a precisely calibrated and tightly collimated stream of aqueous ocular medication microdroplets. The system is designed to reliably administer any selected microdose, which can approach nanoliter scale. The MiDD demonstrably administers volumes down to $1.5 \mu \mathrm{L}$ while maintaining a coefficient of variation below $15 \%(\mathrm{I} .6 \pm 0.2 \mu \mathrm{L} ; \mathrm{CV}=12.5 \%)^{7}$

Abbreviation: MiDD, MicroDose dispenser.

\section{Statistical analyses}

Device performance outcomes were analyzed using descriptive statistics. IOP outcomes were analyzed as the mean change in diurnal IOP on Day 1 and Day 2 compared to premedication baseline diurnal IOP using a paired two-tailed $t$-test, with $P<0.05$ considered to be a statistically significant difference. Left and right eyes of each subject were averaged prior to performing calculations to provide a single mean IOP value per subject for each time point.

\section{Results}

\section{Subject selection and demographics}

A total of 30 subjects (healthy volunteers) were enrolled and received treatment bilaterally. After enrollment, one subject was found to have been taking a systemic antihypertensive medication and was excluded from IOP analyses due to the possible confounding IOP-lowering effect of the systemic medication. Thus, 29 subjects (58 eyes) were evaluable for IOP analyses. All subjects received pre-protocol treatment and completed the study. No subject was discontinued from the study due to medical emergency, development of serious AEs, use of prohibited medication, or pregnancy.

Mean cohort age was $35.6 \pm 10.0$ years, with $57 \%$ females (Table 1). Baseline mean unmedicated diurnal IOP of all evaluable subjects was $17.09 \pm 0.95 \mathrm{mmHg}$.

\section{IOP lowering}

For the 29 IOP-evaluable subjects, excluding the subject on systemic beta-blockers, mean bilateral diurnal IOP was reduced from the unmedicated baseline level by $25.7 \%$ on Day 1 (from $17.1 \pm 0.9$ to $12.7 \pm 1.1 \mathrm{mmHg} ; P<0.0001$ ) and by $29.6 \%$ on Day 2 (from $17.1 \pm 0.9$ to $12.0 \pm 1.2 \mathrm{mmHg}$; $P<0.0001$; Figure 2). Diurnal IOP values significantly differed between medicated Days 1 and $2(P<0.0001)$. The individual IOP measurements at four time points per day confirmed this trend (Figure 3). As is standard in IOPlowering studies, the outcome was the mean diurnal IOP based on the averaged three measurements subsequent to treatment. The IOP measured in left and right eyes never

Table I Demographics and medical histories of study subjects

\begin{tabular}{|l|l|}
\hline Parameter & Value $\mathbf{( N = 3 0 )}$ \\
\hline $\begin{array}{l}\text { Age (years) } \\
\text { Mean } \pm \text { SD } \\
\text { Range }\end{array}$ & $35.6 \pm 10.0$ \\
\hline Female, $\mathrm{n}(\%)$ & $21.3-58.9$ \\
\hline $\begin{array}{l}\text { Self-identified race, } \mathrm{n}(\%) \\
\text { White }\end{array}$ & $17(57)$ \\
African American & $13(45)$ \\
Indian & $\mathrm{I} 6(52)$ \\
\hline Systemic $\beta$-blocker use, $\mathrm{n}(\%)$ & $\mathrm{I}(3)$ \\
\hline Ocular medication use, $\mathrm{n}(\%)$ & $\mathrm{I}(3)$ \\
\hline
\end{tabular}




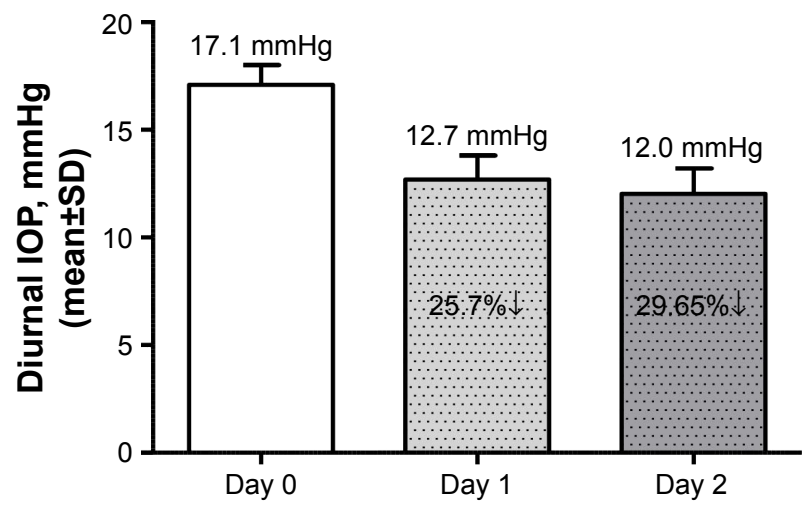

Figure 2 Mean diurnal IOP at baseline (unmedicated), Day I, and Day 2 after 0.4 $\mu \mathrm{g}$ of $0.005 \% \mu \mathrm{Rx}$-latanoprost morning microdosing and percentage change in mean diurnal IOP on Day I and Day 2 from the baseline.

Note: Data derived from the left/right eye average measurements for 29 evaluable subjects.

differed by more than $3 \mathrm{mmHg}$ in any subjects at any time point and was within $2 \mathrm{mmHg}$ for $>99 \%$ of the time (data not shown). Diurnal IOP reduction by $\geq 20 \%$ of baseline diurnal IOP occurred in $83 \%$ of subjects on postmedication Day 1 and in $100 \%$ of subjects on Day 2 (Figure 4).

\section{Microdose delivery success and comfort}

Microdose administration was successful in $100 \%$ of technician-administered topical treatments $(\mathrm{n}=150$ microdose deliveries); $5 \%$ of administrations required an additional administration because of patient's blinking or head movement (data not shown). There were no cases of unintentional overdosing, tear fluid overflow, or dispenser tip/nozzle touching the eye. Subjects did not report negligible discomfort

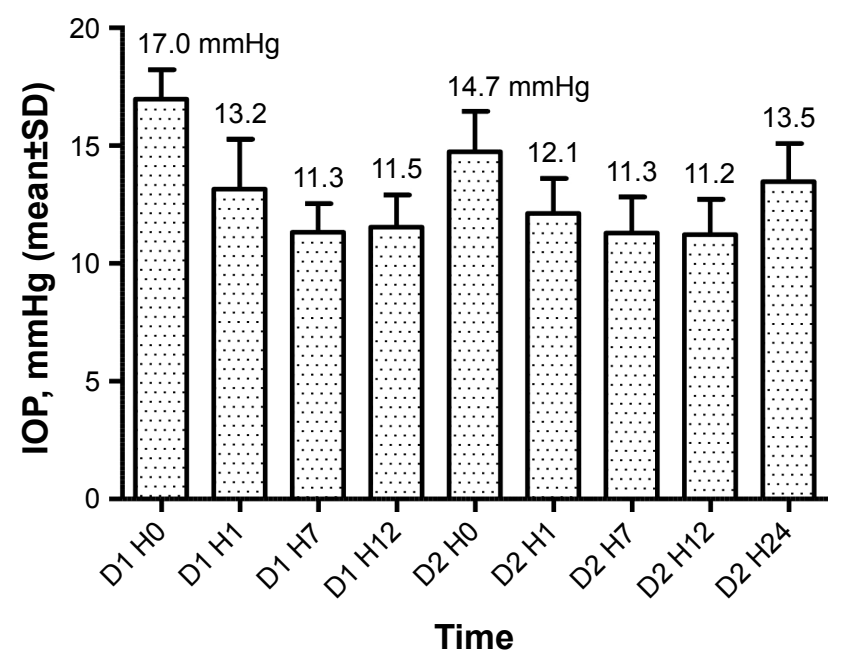

Figure 3 Mean diurnal IOP for average of left and right eyes after morning microdosing with $8 \mu \mathrm{L}$ of $0.005 \% \mu R x$-latanoprost ( $0.4 \mu \mathrm{g}$ total dose).

Note: $\mathrm{N}=29$ evaluable subjects.

Abbreviations: $\mathrm{D}$, day; $\mathrm{H}$, hour.

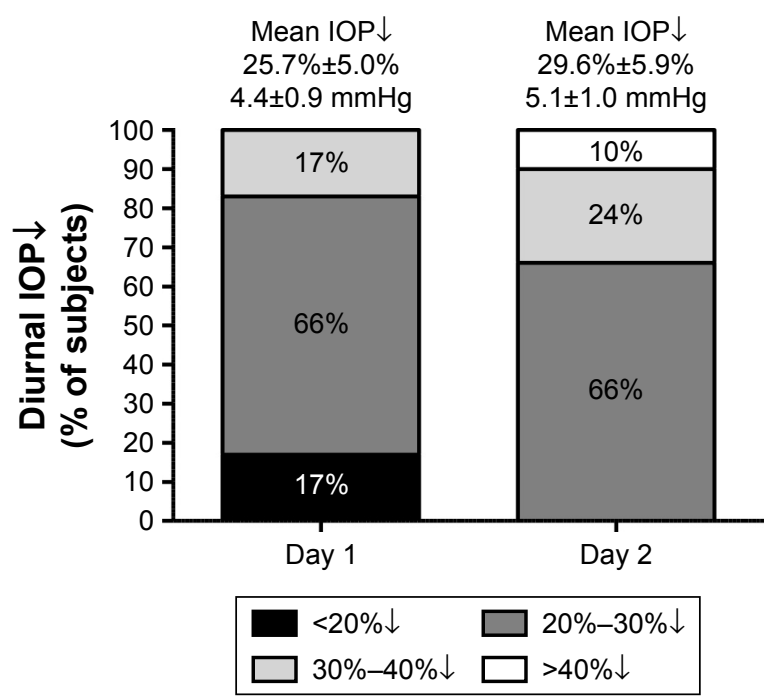

Figure 4 Percent diurnal IOP reduction with $8 \mu \mathrm{L}$ of $0.005 \% \mu \mathrm{Rx}$-latanoprost (0.4 $\mu$ g total dose).

Note: $\mathrm{N}=29$ evaluable subjects.

after $\mu \mathrm{Rx}$ latanoprost dosing, and none of the subjects experienced ocular discomfort from topical microdroplet administration. On a progressive discomfort evaluation scale of $0-100$ points (with 0 points meaning no discomfort), subjects reported scores of $2.0 \pm 5.0$ points on Day 1, which did not significantly change at $3.0 \pm 5.0$ points on Day 2 $(P=0.638)$. Investigator-observed subject self-administered microdosing was successfully performed by all subjects after training, and $88 \%$ of self-administrations were successful on first attempt with the remaining $12 \%$ successfully completed on second attempt.

\section{AEs}

Subjects underwent a slit lamp examination at screening, which was repeated on each study drug administration day both prior to drug administration and 1 hour postdrug administration. No AEs and no clinically significant observations were reported during any of the slit lamp examinations performed during the study. Periocular examination did not reveal any effect (eg, eyelid erythema) of mistargeted doses in patients who blinked or moved during administration. No patient reported stinging, burning, or other irritating sensations on delivery of $\mu \mathrm{Rx}$-latanoprost.

\section{Discussion}

This study demonstrates the excellent feasibility, effectiveness, and appropriateness of administering topical microdoses of glaucoma medication to the ocular surface using a novel system for horizontal, piezo-print microdroplet delivery. 
The high clinical performance of the system for topical drug delivery is further demonstrated by a significant corresponding pharmacodynamic effect of using $\mu \mathrm{Rx}$-latanoprost to lower IOP.

Microdosing system delivery was successful for all patients when performed by a technician in the office setting. Almost all of the cases requiring additional study medication administration occurred on the initial drug administration day and are considered to be a function of the technician's learning curve related to counseling patients on eye alignment. Subject self-administration after receipt of training was similarly successful. In all successful topical administrations with the microdroplet spray, no part of the MicroDose dispenser (MiDD) touched the eye or the periocular area. In comparison, studies of conventional eyedropper delivery demonstrate significant variability in dosing administration efficacy. ${ }^{9-16}$ Even in experienced eye drop users who had been prescribed and had used eye drops for more than 6 months, $20 \%$ of "compliant" patients missed their eye entirely on the first attempt, with most failing to realize that they had missed the dose. ${ }^{11}$ In another study, glaucoma patients used an average of 1.8 \pm 1.2 drops (range, 1-8 drops) in each ultimately successful attempt, ${ }^{9}$ most of which was wasted outside the eye; this may explain why many patients run out of their drops well ahead of their monthly prescription period. In these studies, patients accurately self-delivered the prescribed dose in only $7 \%-39 \%$ of attempts. ${ }^{9-13}$ About $33 \%-76 \%$ of patients touched their periocular tissue or the globe with the eye drop bottle tip., ${ }^{9,10,12}$ An eyedropper tip touching the ocular surface can cause corneal abrasions, and contact with either the globe or surrounding tissues can cause eyedropper bottle contamination with bacteria. One study reported that bacterial contamination occurred in $19 \%$ of eye drops used for $<8$ weeks and in $40 \%$ of bottles used $>8$ weeks. ${ }^{17}$ In the elderly, the problem is even more palpable: one study reported that one-third of the surveyed persons aged 75 years or older living alone and more than half of those applying eye drops by themselves did so with poor success. ${ }^{14}$ Even in more functional healthy patients undergoing routine cataract surgery and who were prescribed several weeks of postoperative eye drops, $92 \%$ displayed improper administration technique including missing the eye (31\%), incorrect instillation amount (64\%), and contamination of the bottle $(57 \%) .{ }^{15}$

Patients consistently rated microdosing to be essentially without discomfort. No reported or investigator-identified AEs occurred. These findings are congruent with earlier demonstrations of the excellent utility of the MiDD system for comfortably delivering multiple $8-\mu \mathrm{L}$ microdoses of other ocular medications (eg, phenylephrine). ${ }^{7,8}$

The results of this clinical trial of $\mu \mathrm{Rx}$-latanoprost demonstrated a high success rate of ocular microdose delivery, further evidenced by the robust IOP-lowering effect of microdosing at a fraction of the volume and total therapeutic dose of standard eye drops $(75 \%$ lower than conventional eyedropper doses) with almost $30 \%$ reduction in diurnal IOP through 48 hours in once daily microdosed healthy volunteers. The occurrence of $13 \%$ additional diurnal IOPlowering effect (absolute IOP difference of 5\%) on Day 2 compared to that on Day 1 may indicate an incrementally increasing effect in the first days of $\mu \mathrm{Rx}$-latanoprost delivery, and a long-term IOP reduction with microdosing might result in even further IOP reduction after stabilization of cumulative ocular responses. Future investigations are needed to study the long-term response.

Our IOP-lowering findings are consistent with the effect previously reported in the peer-reviewed literature using standard eyedropper-delivered $0.005 \%$ latanoprost in a similar setting of healthy volunteers. In one study of 28 healthy volunteers, conventional eyedropper-administered $0.005 \%$ latanoprost achieved 26\% IOP-lowering effect in the first 2 days. ${ }^{17}$ Similarly, in another study, eyedropper-delivered $0.005 \%$ latanoprost achieved 24\% IOP-lowering effect in healthy volunteers. ${ }^{18}$ Thus, our 26\% Day 1 and 30\% Day 2 IOPlowering effects with $\mu \mathrm{Rx}$-latanoprost are consistent with the level of IOP reduction previously reported after eyedropper overdosing of approximately fourfold larger total latanoprost doses. The significance of the diurnal IOP values differences between medicated Days 1 and $2(P<0.0001)$ indicate that there could be further IOP reduction with long-term treatment until reaching a stable and minimum IOP trough.

This study further confirms the growing evidence from peer-reviewed literature that clinically meaningful therapeutic effect can be achieved by using smaller fractional doses of topical medications that spare the eye from drug and preservative overdose. Microvolumes as low as $2-5 \mu \mathrm{L}$ have demonstrated compelling pharmacodynamic effect similar to conventional overdosing with eye drops. ${ }^{19-21}$ More physiologic microdosing studies that better match the tear film capacity of 6-8 $\mu \mathrm{L}$ have also demonstrated high potency and biologic effect. ${ }^{22-24}$

The current study, along with the two prior clinical trials of piezo-print microdosing, ${ }^{7,8}$ demonstrates a broad range of therapeutic applicability of ocular drug delivery with a high-precision horizontal microjet. The ocular microdosing approach can produce an equivalent biologic effect compared 
to established eyedropper therapies while improving dosing precision, accuracy, and delivery success rate. This study expands our understanding of biologically appropriate dosing for front-of-the-eye therapies and further suggests the usefulness of microdosing to improve the therapeutic index of many topically administered ocular pharmacologics.

Despite the new clinical insights and the informative nature of this study, its limitations are the short-term nature of the patient's follow-up and the healthy volunteer officebased setting that may not be representative of other patient populations and long-term home use. Although the biologic effect of microdosed latanoprost on IOP-lowering effect is significant, this study did not directly compare microdosing of $0.4 \mu \mathrm{g}$ of $\mu \mathrm{Rx}$-latanoprost to $1.6 \mu \mathrm{g}$ dosing of standard eyedropper in a randomized controlled fashion, which we plan to do in future studies.

In conclusion, ocular microdosing with high-precision piezo-ejection delivery systems can be easily performed by a technician or a patient with a high rate of success. Microdosing of an 8- $\mu \mathrm{L}$ drop volume containing $0.4 \mu \mathrm{g}$ of $\mu \mathrm{Rx}$-latanoprost achieved comparable IOP reduction with the levels previously observed with eyedropper overdosing. Lower ocular exposure with topical prostaglandin analog microdosing can enable new therapeutic opportunities for optimizing glaucoma treatment. Microdosing may be useful for reducing ocular overexposure to other ophthalmic drugs that are used to treat various other ocular diseases.

\section{Future perspectives}

Eyenovia's high-precision piezo-print microdosing approach is widely applicable for treating many front-of-the-eye diseases such as glaucoma, dry eye, allergic eye disease, and many ocular pathologies with infectious and immunologic etiologies. Topical side effects such as conjunctival hyperemia, discomfort, irritation, prostaglandin-associated periorbitopathy are dose related and can be significantly reduced with high-precision targeted microdosing. Also, the electronic piezo-delivery platform opens immense possibilities for eHealth and patient monitoring, compliance tracking, and customized treatment approaches.

\section{Executive summary}

Conventional eyedroppers deliver oversized doses that exceed the eye's absorptive and storage capacities

- Trigger reflex blinking and tearing.

- Drug loss to spillage and increased drainage.

- Medication dilution from tearing.
- Overflow can irritate skin and eyelids.

- Nasolacrimal mucosal absorption can cause systemic side effects.

- No hepatic first-pass metabolism.

- Cardiopulmonary and neurological risks with common topical ocular medications.

- Children and elderly are at particularly high risk of systemic AEs.

Piezoelectric delivery can precisely deliver single-microliter microdoses

- Overflow, ocular irritation, and reflex blinking/tearing reduced.

- Less drug loss and medication dilution.

- Increased bioavailability to the eyes.

- Reduced local drug reactions.

- User friendliness may increase compliance with ocular dosing regimens.

- Systemic drug absorption and related side effect risk are decreased.

Microdosing delivers robust IOP-lowering effect with $\mu R x$ latanoprost at a fraction of the dose

- Almost 30\% diurnal IOP-lowering effect over 2 days with single $0.4 \mu \mathrm{g}$ dose (a quarter of conventional eyedropper).

- Piezoelectric microdosing technology may be modified to deliver glaucoma and dry eye medications, antibiotics, analgesics, biologics, gene therapy vectors, nanoparticles, and corneal/limbal stem cells.

\section{Acknowledgments}

The authors thank Matthew Silverman, MSci, PhD (Biomedical Publishing Solutions, Delray Beach, FL, USA) for scientific, analytical, and writing assistance. The corporate sponsor of the study, Eyenovia, Inc., compensated the site for the enrollment and follow-up of patients.

\section{Disclosure}

The authors do not have any conflicting relationships with the study site in Panama. Dr Ianchulev is a chief medical officer of Eyenovia, Inc. Drs Kramm, Pasquale, Lin, Tsai, and Weinreb are clinical consultants/advisors for Eyenovia, Inc. The authors report no other conflicts of interest in this work.

\section{References}

1. Washington N, Washington C, Wilson CG. Ocular drug delivery. In: Physiological Pharmaceutics: Barriers to Drug Absorption. 2nd ed. Boca Raton, FL: CRC Press; 2001:249-270. 
2. Mishima S, Gasset A, Klyce SD, Baum JL. Determination of tear volume and tear flow. Invest Ophthalmol. 1966;5(3):264-276.

3. Scherz W, Doane MG, Dohlman CH. Tear volume in normal eyes and keratoconjunctivitis sicca. Albrecht Von Graefes Arch Klin Exp Ophthalmol. 1974;192(2):141-150.

4. Izazola-Conde C, Zamora-de La Cruz D, Tenorio-Guajardo G. Ocular and systemic adverse effects of ophthalmic and non ophthalmic medications. Proc West Pharmacol Soc. 2011;54:69-72.

5. Quaranta L, Gandolfo F, Turano R, et al. Effects of topical hypotensive drugs on circadian IOP, blood pressure, and calculated diastolic ocular perfusion pressure in patients with glaucoma. Invest Ophthalmol Vis Sci. 2006;47(7):2917-2923.

6. Novack GD, O’Donnell MJ, Molloy DW. New glaucoma medications in the geriatric population: efficacy and safety. J Am Geriatr Soc. 2002; 50(5):956-962.

7. Ianchulev T, Chayet A, Kahook M, Packer M, Pasquale L, Weinreb RN Pharmacodynamic profile of mydriatic agents delivered by ocular piezo-ejection microdosing compared with conventional eyedropper. Ther Deliv. 2016;7(11):751-760.

8. Ianchulev T, Weinreb R, Tsai JC, Lin S, Pasquale LR. High-precision piezo-ejection microdosing of topical ocular medications: Phase II study on local and systemic effects of phenylephrine. Ther Deliv. 2018; 9(1):17-27.

9. Gupta R, Patil B, Shah BM, et al. Evaluating eye drop instillation technique in glaucoma patients. J Glaucoma. 2012;21(3):189-192.

10. Gomes BF, Paredes AF, Madeira N, Moraes HV, Santhiago MR. Assessment of eye drop instillation technique in glaucoma patients. Arq Bras Oftalmol. 2017;80(4):238-241.

11. Stone JL, Robin AL, Novack GD, Covert DW, Cagle GD. An objective evaluation of eyedrop instillation in patients with glaucoma. Arch Ophthal. 2009;127(6):732-736.

12. Hennessy AL, Katz J, Covert D, et al. A video study of drop instillation in both glaucoma and retina patients with visual impairment. Am J Ophthalmol. 2011;152(6):982-988.

13. Davis SA, Sleath B, Carpenter DM, et al. Drop instillation and glaucoma. Curr Opin Ophthalmol. 2018;29(2):171-177.
14. Burns E, Mulley GP. Practical problems with eye-drops among elderly ophthalmology outpatients. Age Ageing. 1992;21(3):168-170.

15. Ja A, Kasner O, Samek DA, Lévesque V. Evaluation of eyedrop administration by inexperienced patients after cataract surgery. $J$ Cataract Refract Surg. 2014;40(11):1857-1861.

16. Geyer O, Bottone EJ, Podos SM, Schumer RA, Asbell PA. Microbial contamination of medications used to treat glaucoma. Br JOphthalmol. 1995;79(4):376-379.

17. Lindén C, Alm A. The effect on intraocular pressure of latanoprost once or four times daily. Br J Ophthalmol. 2001;85(10):1163-1166.

18. Larsson L. Intraocular pressure over 24 hours after single-dose administration of latanoprost $0.005 \%$ in healthy volunteers. A randomized, double-masked, placebo controlled, cross-over single center study. Acta Ophthalmol Scand. 2001;79(6):567-571.

19. van der Heiden H, Amar T, Lichtenauer WF. Plasma and ocular pharmacokinetic study comparing $3 \mu \mathrm{L}$ micro-drop to typical $40 \mu \mathrm{L}$ drop volume of timolol $0.5 \%$ in pigmented rabbits. Invest Ophthalmol Vis Sci. 2014;55:453.

20. Elibol O, Alçe T, Yüksel N, Çaĝlar Y. The influence of drop size of cyclopentolate, phenylephrine and tropicamide on pupil dilatation and systemic side effects in infants. Acta Ophthalmol Scand. 1997;75(2): $178-180$.

21. Gray RH. The influence of drop size on pupil dilatation. Eye. 1991;5(5): 615-619.

22. Brown RH, Wood TS, Lynch MG, et al. Improving the therapeutic index of topical phenylephrine by reducing drop volume. Ophthalmology. 1987;94(7):847-850.

23. Lal A, Kataria V, Rajpal A, Khanna N. Pharmacodynamic effects of pilocarpine eye drop enhanced by decreasing its volume of instillation. Indian J Physiol Pharmacol. 1995;39(3):267-270.

24. Lynch MG, Brown RH, Goode SM, Schoenwald RD, Chien DS Reduction of phenylephrine drop size in infants achieves equal dilation with decreased systemic absorption. Arch Ophthal. 1987;105(10): 1364-1365.
Clinical Ophthalmology

\section{Publish your work in this journal}

Clinical Ophthalmology is an international, peer-reviewed journal covering all subspecialties within ophthalmology. Key topics include: Optometry; Visual science; Pharmacology and drug therapy in eye diseases; Basic Sciences; Primary and Secondary eye care; Patient Safety and Quality of Care Improvements. This journal is indexed on

\section{Dovepress}

PubMed Central and CAS, and is the official journal of The Society of Clinical Ophthalmology (SCO). The manuscript management system is completely online and includes a very quick and fair peer-review system, which is all easy to use. Visit http://www.dovepress.com/ testimonials.php to read real quotes from published authors. 